\title{
Mindfulness-Based Program for Autism Spectrum Disorder: a Qualitative Study of the Experiences of Children and Parents
}

\author{
Anna Ridderinkhof ${ }^{1,2} \cdot$ Esther I. de Bruin ${ }^{1,2}$ (D) René Blom ${ }^{3} \cdot$ Nirbhay N. Singh ${ }^{4}$. Susan M. Bögels ${ }^{1,5}$
}

Published online: 16 July 2019

(C) The Author(s) 2019

\begin{abstract}
Objectives Mindfulness-based programs could support children with autism spectrum disorder (ASD) and their parents to cope with autism spectrum symptoms and reduce comorbid mental health problems. In this study, we aimed to explore which change processes are involved in a mindfulness-based program for children with ASD and their parents (MYmind), according to a qualitative analysis of the families' experiences.

Method Fourteen children aged 9-17 years and 31 parents (18 mothers, 11 fathers, 2 caring relatives) participated in an interview 2 to 5 months after the 9-week MYmind training, about their experiences with the training, experienced changes, and how mindfulness works for them. We used constructivist grounded theory methodology to develop a theory of the key change processes and their relations.

Results Eight main change processes resulted from the analysis, namely connecting with peers, pausing, being aware, being in the here and now, letting be, determining a strategy, being and responding calm, and attuning to others. We proposed a model reflecting the interdependency and direction of these change processes.

Conclusion The findings deepen our understanding of how multiple change processes are involved in the MYmind program for children with ASD and their parents. Theoretical and research implications are discussed.
\end{abstract}

Keywords Autism spectrum disorder · Mindfulness · Mindfulness-based program · Qualitative study · Grounded theory $\cdot$ Change processes

Many families of children with autism spectrum disorder (ASD) are in need of support to cope with daily challenges. Children with ASD experience difficulties in social interactions and high rates of stress and comorbid symptomssuch as attention-deficit/ hyperactivity disorder (ADHD)anxietyand depression

Esther I. de Bruin

e.i.debruin@uva.nl

1 Research Institute of Child Development and Education, University of Amsterdam, Amsterdam, The Netherlands

2 Research Priority Area Yield, University of Amsterdam, Amsterdam, The Netherlands

3 Karakter Child and Adolescent Psychiatry Center, Zwolle, The Netherlands

4 Department of Psychiatry and Health Behavior, Medical College of Georgia, Augusta University, Augusta, GA, USA

5 Department of Developmental Psychology, University of Amsterdam, Amsterdam, The Netherlands
(American Psychiatric Association [APA] 2013; Corbett and Simon 2014; Simonoff et al. 2008). Parents of children with ASD also experience heightened stress and mental health problems (e.g.Hastings 2003; Van Steijn et al. 2014). Emerging evidence indicates that mindfulness-based programs (MBPs) are potentially promising; MBPs might reduce social communication problems in children with ASD and mental health problems in both children with ASD and their parents (reviewed by Cachia et al. 2016ab). Howeverwhether and how MBPs benefit children with ASD and their parents is in the beginning stages of research

Mindfulness is defined as the self-regulation of attention to direct experiences in the present moment, including senses, thoughts, feelings, and bodily sensations, and orienting to these experiences with an open, curious, and accepting attitude (Bishop et al. 2004; Kabat-Zinn 1994). This is practiced in MBPs, of which mindfulness-based stress reduction (MBSR; Kabat-Zinn 1982) and mindfulness-based cognitive therapy (MBCT; Segal et al. 2012) are the most well-studied programs. MBSR was developed to decrease distress in people with chronic pain, stress, and other diseases (Baer 2003; 
Bohlmeijer et al. 2010), and MBCT was developed to reduce the risk for relapse in people with recurrent depression (Kuyken et al. 2016; Ma and Teasdale 2004). Based on these MBPs in mental health care, the MYmind program was developed for clinically referred youngsters with social, behavior, and attention problems diagnosed with ASD, ADHD, oppositional-defiant (ODD), or conduct disorder (CD) and their parents (Bögels et al. 2008), and then tailored specifically to youngsters with ADHD (Van der Oord et al. 2012; Van de Weijer-Bergsma et al. 2012) or ASD (De Bruin et al. 2015) and their parents. In MYmind, children with ASD and their parents follow parallel sessions, in which they practice mindfulness meditations and applications of mindfulness during challenging situations.

Mindfulness training might benefit children with ASD in several ways. In MBPs, participants learn to widen their attention and to improve their control over attention (Bishop et al. 2004; Hölzel et al. 2011; Lutz et al. 2008). This might improve underlying neurocognitive deficits of ASD, such as central coherence and executive functioning. Weak central coherence refers to a deficit in integrating information into a coherent image and an overly detail-focused information processing style (Happé and Frith 2006), and weak executive functioning refers to difficulties in planning, cognitive flexibility, inhibition, and working memory (Hill 2004). Furthermore, MBPs could improve social interaction by increased emotional awareness and understanding (Block-Lerner et al. 2007; Sequeira and Ahmed 2012). Also, MBPs may improve the coping abilities of children with ASD and their parents, by changing their relationship with distressing situations, feelings, and thoughts to be less judgmental, more accepting, and more compassionate (Bishop et al. 2004; Bögels and Restifo 2014; Segal et al. 2012). Furthermore, MBPs may change the negative interaction pattern between parental mental health problems and children's comorbid mental health and behavioral problems (e.g., Hastings 2002) by using a parallel program for both children with ASD and their parents.

The few small-scale studies investigating MBPs for children with ASD indicate reduced anxiety, thought problems, and aggression, and increased social responsiveness and wellbeing (reviewed by Cachia et al. 2016a and Semple 2019). Studies investigating MBPs for parents of children with ASD indicate reduced parental stress and increased parental psychological well-being, as well as improved child behavior (Cachia et al. 2016b; Dykens et al. 2014; Neece 2014). Three studies combined the training of children and parents, indicating the aforementioned improvements for children and parents, as well as improved parenting behavior (De Bruin et al. 2015; Hwang et al. 2015; Ridderinkhof et al. 2018a, b).

These studies addressed the question if mindfulness could work on specific a priori hypothesized outcomes. To answer the question on what and how mindfulness works for children with ASD and their parents, next to testing hypotheses on specific mechanisms of change with quantitative studies, a qualitative approach is of complementary value. Qualitative research is grounded in participants' experiences, which helps to understand the processes of change inductively (Charmaz 2014). Insight and understanding into the experiences of children with ASD and their parents increases our understanding of ASD and the appropriateness of our services (e.g., Billington 2006). Listening to their personal experiences could help to understand how they give meaning to the MYmind program. Also, mindfulness is primarily an internal experience. The way people relate to their internal thoughts, feelings, bodily sensations, and action tendencies are the target of MBPs (Bishop et al. 2004; Teasdale et al. 2002). Therefore, in addition to quantitative outcome studies, including a qualitative approach to investigate the experiences of children with ASD and their parents who participate in MYmind may provide unique information and deepen our understanding about how this program works for them.

Some studies have included qualitative analyses in their investigation of MBPs for children with ASD or their parents. In a series of single-case studies of a mindfulness-based positive behavior support (MBPBS) training for three mothers of adolescents with ASD, Singh et al. (2014) included a qualitative analysis of informal interviews. Mothers indicated that their stress decreased, and challenging behaviors of the children decreased and their compliance increased. The program enabled the mothers to respond with calmness and more appropriately to the needs of their child. They experienced an increasingly warmer relationship with their children with ASD and other family members. Also, mothers experienced more joy in their lives and a better understanding of themselves and others. A repeated measures study of MYmind included a qualitative analysis of written answers by children and parents on open-ended evaluation questions (Ridderinkhof et al. 2018a), resulting in three main themes with regard to experienced changes described by children with ASD and their parents. Mindfulness skills reflected the mindfulness aspects that children and parents learned. Improved well-being reflected a broad category of experienced changes including improved parent-child interaction, calmness, and coping with difficult experiences. Little to no change was the final and smaller theme.

In a clinical dissertation, seven mothers of children with ASD participated in an interview about their experiences with a mindful parenting course (Kennedy 2017). The category impact of the course indicated increased acceptance, self-compassion, present-moment awareness, impact on other family members, and difficulties with maintaining meditation practices. The category improvements in parent-child relationship and interactions indicated that decreased reactivity and being better able to take their child's perspective positively influenced mother-child interactions and relationships. These results give a first impression of the experiences of children with 
ASD and their parents following an MBP. However, these qualitative studies included either a small sample size only focusing on the mothers (Kennedy 2017; Singh et al. 2014), or a structured questionnaire with written answers instead of in-depth interviewing (Ridderinkhof et al. 2018a).

In the current study, we used grounded theory with a constructivist approach to develop a data-driven provisional theory to answer the research question: Which change processes are involved in MYmind based on the personal experiences of children with ASD and their parents?

\section{Method}

\section{Participants}

The current study is part of a larger study approved by the Medical Ethics Committee of the Academic Medical Center (AMC) in Amsterdam (NL43720.018.13). Quantitative results appeared in previous reports (De Bruin et al. 2015; Ridderinkhof et al. 2018a, b). Children and parents who took part in MYmind at one of the participating treatment centers were asked to participate in this qualitative study. We separately interviewed children, mothers, and fathers. In total 20 different families participated in the interviews, comprising 14 children with ASD and 31 parents (Table 1). Children were between 9 and 17 years old. Parents were between 30 and 67 years old, including 18 mothers, 11 fathers, 1 caring grandmother, and 1 caring aunt. For 19 out of 20 families, at least one of the parents took part in the MYmind program. The interviewed parents that did not take part in MYmind were indirectly involved by their child and partner taking part in MYmind. Also, two of them previously took part in MYmind for ADHD with their other child.

All children had a diagnosis of ASD based on the Diagnostic and Statistical Manual of Mental Disorders (DSM; APA 1994, 2013). The diagnosis was verified by the Autism Diagnostic Observation Schedule (ADOS; Lord et al. 2000, 2012). An inclusion criterion was an IQ $\geq 80$ estimated based on clinical judgment. Exclusion criteria for participating in MYmind were inadequate mastery of the Dutch language, severe behavioral problems as indicated by a classification of $\mathrm{CD}$, current suicidal risk, or psychotic disorder.

\section{Procedure}

We asked the families to participate in this study before they started with the MYmind program. The purpose and procedures were repeated before the start of the interview and written informed consent was obtained. The first author held the interviews between 1 day and 12 weeks after the booster session ( $M=4$ weeks). The interviews were one-on-one, lasted between 12 and 60 minutes $(M=39$ $\min , \mathrm{SD}=13 \mathrm{~min}$ ), and were audiotaped.

\section{MYmind}

The MYmind program is a manualized program (De Bruin et al. 2015; Ridderinkhof et al. 2018a). It includes group sessions of $1.5 \mathrm{~h}$ per week for 9 weeks, with a parallel group for children and parents. It also includes a booster session 9 weeks after the final session for parents and children together. During the 1st, 5th, and 9th session, children and parents start the session together. Each session includes psychoeducation, mindfulness practices, inquiry about the practices, and discussing the daily home practices. During psychoeducation, aspects of ASD, attention, awareness and mindfulness are further explained, sometimes specifically in relation to ASD (i.e., narrow and focused versus wide and open attention).

In the MYmind child program, the practices cultivate focused attention, awareness of inward and outward experiences (such as bodily sensations, feelings, and sounds), self-control, and an open and accepting stance toward experiences. Mindfulness practices consist of breathing meditation, body scan, breathing space, sound meditation, thought meditation, and walking meditation. Also, the program includes informal mindfulness practices applied in role-playing, for example, being aware of bodily sensations during hurrying to school. The themes of the program are tailored to challenges specific for children with ASD, for example, awareness for unexpected changes (e.g., awareness for changes in the training room and their reaction to it), awareness for sounds, and awareness for feelings of self and others. Inquiry is short in the child program, and direct neutral questions, such as "Was this a pleasant, neutral, or unpleasant exercise for you?", are asked if children give little response to open questions about their experiences.

In the MYmind parent program, the practices cultivate focused and enhanced attention, awareness (of bodily sensations, feelings, thoughts, action tendencies, external stimuli, automatic reactions, parents' own boundaries), responding non-automatically in stressful parenting situations, responding with awareness and open-mindedness towards the needs of the child, and (self)compassion in parenting. In addition to the same mindfulness practices in the child program, the MYmind parent program includes meditations on visualizing challenging parenting situations specific to ASD, and informal mindful parenting practices. An example is to observe their child with the quality of a beginner's mind, open, curious, and nonjudgmental, as if having never seen the child before. The program is guided by mental health care professionals are experienced in ASD, who completed an advanced teacher training of MYmind for youngsters with ADHD/ASD and their parents, and engage in personal mindfulness practice. Further 
Table 1 Descriptions of participants

Families $(n=20)$

Relation among interview participants

Child and both parents participated

Child and mother participated

Child and father participated

Child, mother, caring aunt, caring grandmother participated

Mother and father participated

Mother participated

Father participated

Took part in MYmind

Age (mean and SD)

Male

ASD diagnosis of the child

Classic autism

Asperger Syndrome

PPD-NOS

Autism spectrum disorder

Comorbid diagnosis of the child

ADHD

Internalizing disorder ${ }^{\mathrm{a}}$

Dyslexia

Encopresis

ADOS classification of the child

Autism

Autism spectrum disorder

ASD classification unmet

Not available

Medication use ${ }^{b}$

Additional treatment during MYmind

Mental health therapy

(Parent) Counseling

Intensive psychiatric family treatment

Family systems therapy

Additional treatment between final session and booster session

Mental health therapy

Counseling

Intensive psychiatric family treatment

Family systems therapy

Educational type

Regular education

Special education

Educational level

Primary education

Secondary education

Vocational training

Higher professional education

University

Family situation

Married/living together
8

4

1

1

1

4

1

Children $(n=14)$

14

$12.43(2.42)$

$8(57 \%)$

$3(21 \%)$

$1(7 \%)$

$6(43 \%)$

$4(29 \%)$

$3(21 \%)$

$2(14 \%)$

$2(14 \%)$

$1(7 \%)$

$8(57 \%)$

$3(21 \%)$

$3(21 \%)$

0

$5(36 \%)$

$3(21 \%)$

$1(7 \%)$

$1(7 \%)$

$1(7 \%)$

$3(21 \%)$

$2(14 \%)$

$1(7 \%)$

$2(14 \%)$

$12(86 \%)$

$2(14 \%)$

$9(64 \%)$

$3(21 \%)$

$2(14 \%)$

0

0

$9(64 \%)$
Parents ( $n=31$ of 20 children)

22

$43.89(6.76)$

$11(35 \%)$

$4(20 \%)$

$1(5 \%)$

$11(55 \%)$

$4(20 \%)$

$4(20 \%)$

$2(10 \%)$

$2(10 \%)$

$1(5 \%)$

$9(45 \%)$

$5(25 \%)$

$4(20 \%)$

$2(10 \%)$

$\mathrm{n} / \mathrm{a}$

$2(6 \%)$

$5(16 \%)$

$3(10 \%)$

$2(6 \%)$

$\mathrm{n} / \mathrm{a}$

$\mathrm{n} / \mathrm{a}$

$3(10 \%)$

$2(6 \%)$

$\mathrm{n} / \mathrm{a}$

$\mathrm{n} / \mathrm{a}$

0

$6(19 \%)$

$5(16 \%)$

$9(29 \%)$

$11(36 \%)$

$22(71 \%)$ 
Table 1 (continued)

\begin{tabular}{lll}
\hline Divorced/separated with co-parenting & $3(21 \%)$ & $4(13 \%)$ \\
Otherwise & $2(14 \%)$ & $5(16 \%)$ \\
Working situation parents & & $14(45 \%)$ \\
Full time & $\mathrm{n} / \mathrm{a}$ & $10(32 \%)$ \\
Part time & $\mathrm{n} / \mathrm{a}$ & $7(23 \%)$ \\
Not working $^{\mathrm{c}}$ & $\mathrm{n} / \mathrm{a}$ & $43.26(11.73)$ \\
Interview time in minutes (mean and SD) $_{\text {Interview timing (weeks after booster session) }}$ & $30.14(11.48)$ & $4.00(2.84)$ \\
Interview location & $3.57(2.47)$ & $13(42 \%)$ \\
Home & & $16(52 \%)$ \\
Treatment center & $6(43 \%)$ & $1(3 \%)$ \\
University lab & $8(57 \%)$ & $1(3 \%)$ \\
Video call & 0 & 0 \\
\hline
\end{tabular}

$A D H D$, attention-deficit/hyperactivity disorder; $A S D$, autism spectrum disorder; $P P D-N O S$, pervasive developmental disorder — not otherwise specified; $S D$, standard deviation. ${ }^{\mathrm{a}}$ Internalizing disorders included depressive disorder or general anxiety disorder. ${ }^{\mathrm{b}}$ Medication was indicated for attention problems, depression or anxiety symptoms, or oversensitivity. ${ }^{\mathrm{c}}$ The "not working category" includes participants that described themselves as housewives, long-term ill, or unemployed

details about each session of the MYmind's curriculum are described in previous studies (De Bruin et al. 2015; Ridderinkhof et al. 2018a).

\section{Interview}

The interview contained five main questions: (1) What does mindfulness mean to you?, (2) How did you experience the mindfulness training?, (3) Has anything changed for you through the mindfulness training? If so, what?, (4) How does mindfulness help you?, and (5) Has anything changed for your mother/father/co-parent/child through the mindfulness training? If so, what? For the parents who did not participate in the MYmind program (as only one of the parents needed to participate), the fifth question was explored more in depth, whereas for the third question, it was explored whether and what had changed indirectly through having their family member(s) taking part in the training. The interviewer prompted and asked clarifying questions to elicit further information (e.g., Could you tell me something more about that?, How do you notice?). The interview schedule contained a list of more specific open-ended questions for each main question to use when participants responded briefly to the main question and prompts (e.g., What parts of the training were helping for you? What parts were difficult? Did you notice any change in your feelings, or how you deal with your feelings? How does mindfulness help with [experienced change]?). Following the theoretical sampling guidelines of grounded theory (Charmaz 2014), we added additional prompts and clarifying questions for later interviews with other participants (e.g., What do you mean by taking a moment/taking rest? Is taking distance a physical distance or mental distance?), based on the qualitative analyses conducted so far.

The grounded theory provides a structured method to analyze actions and processes through an inductive iterative process of constant comparison, aiming for theory development grounded in participants' experiences (Charmaz 2014; Glaser and Strauss 1967). In the grounded theory, concepts are viewed as temporary and research as a developing process, corresponding to how phenomena are viewed according to the Buddhist foundations of mindfulness (Shonin et al. 2015). As opposed to classic grounded theory (Glaser and Strauss 1967), according to the constructivist approach grounded theories do not emerge from the data independently from the researcher, but instead researchers construct grounded theories in interaction with the data (Charmaz 2014).

\section{Data Analyses}

We used a constructivist grounded theory approach to analyze the data (Charmaz 2014). The first author and student assistants transcribed the interviews. The first author subsequently coded all interviews in ATLAS.ti. She started with line-by-line analyses and line-by-line open coding of the first six interviews with parents. Then, she used open coding of meaningful segments to code the first six interviews with parents and the first six interviews with children, which entailed dividing the interviews into meaningful segments based on their content and then labeling them with a code that reflected that content. Codes were kept close to the data and data segments were mainly labeled for the action or process at issue in the segment. Data segments were constantly compared with previous data segments and previous codes to determine whether the data segment could be labeled with one of the previous codes. To verify the coding, the second author read through the open coding of the first two parent interviews and the first two child interviews. The first and second author discussed the coding and adjusted it based on this discussion for the first 12 interviews (six parents and six children).

The first author selected segments that were relevant for answering the research question, and compared, combined, modified, or renamed the codes. This started the process of constructing categories by grouping the codes into categories that seemed 
to apply to the same process, and naming each category. Thus, data segments were building blocks for the codes, and in turn, the codes were building blocks for the categories. All authors then discussed the emerging categories, and where needed the first author adjusted the categories based on these discussions and comparisons to the codes and data segments. Then she coded the other 33 interviews using focused coding. This entailed coding on what was relevant for the research question, selectively coding around the emerging categories, constantly comparing the categories, codes, and new data segments, and thereby explicating the meaning of the categories. Also, segments that showed relations between the categories were coded accordingly. The first author constructed a model of the core categories and their relations. Again, all authors discussed this model and examples of all steps in the analysis. The first author made a final round of comparison of data segments to codes, codes to codes, codes to categories, and categories to categories, resulting in the final model. During the entire process, written memos helped to develop ideas about the categories and their relations, and to keep track of questions that arose that could help explicate the categories. These questions gave direction for additional clarifying questions in later interviews and comparison with previously coded interviews, following guidelines of theoretical sampling.

The authors acknowledge their unique orientations to the analyses and brought these perspectives to it. The first author (AR) is a researcher in mindfulness and developmental psychopathology, and a beginning mindfulness trainer. The second author $(\mathrm{EdB})$ is a researcher in mindfulness and mental health care, a more experienced mindfulness trainer, developed the MYmind program for youngsters with ASD, and is a health care psychologist. The third author (RB) is a very experienced mindfulness trainer and a psychomotor therapist with expertise in ASD. The fourth author (NNS) is a researcher in mindfulness, psychiatry and health behavior, a very experienced mindfulness trainer, a behavior analyst, and a Buddhist practitioner. The fifth author (SB) is a researcher in mindfulness and developmental psychopathology, a very experienced mindfulness trainer, and a psychotherapist. She designed a mindful parenting program and the MYmind program for youngsters with ADHD, and she supervised other mindfulness trainers involved in this study. During the discussions, we attempted to question the possible influence of these backgrounds on the analytic process and attempted to keep the analyses close to the data.

\section{Results}

The emergent grounded theory model consisted of eight categories that described the change processes constructed from the data. The eight change processes were connecting with peers, pausing, being aware, being in the here and now, letting be, determining a strategy, being and responding calm, and attuning to others. First, a description and example quotes of each change process is given. Second, the relations among them are described.

\section{Connecting with Peers}

Most children mentioned that they connected with other group members. They enjoyed to chat with each other and explained that if alone in the training there would be less joy. One child appreciated recognizing himself in the other children, saying:

They were not really different, they were a bit the same.

This seems an indication of common humanity. Some parents also mentioned that their child recognized similarities in other children and connected with other children. A couple of children described that they could exchange experiences with other children, understand each other, and could give advice. However, one child and parents of some children expressed that the children had little or no connection with other group members.

Most parents mentioned that they connected with other group members. They valued recognizing situations from each other and hearing the solutions that other parents used for situations that were applicable to their own children. They felt understood by other parents experiencing similar situations. Also, they valued exchanging experiences about the meditations and training, which in turn gave them ideas on how they could apply the training. However, one parent experienced listening to the stories of other parents as interesting, but did not think it helped him and did not experience a bond with the other parents. None of the parents that did not take part in the MYmind sessions themselves mentioned connecting with peers as a change process. Around half of the parents expressed a sense of common humanity in relation to exchanging experiences. For example:

I heard stories that made me think: Indeed, that also happens to me, it is not always easy, and occasionally you lose your patience. It is just pleasant that I am not the only one who experiences that.

By hearing from other parents I realized that we are not the only ones who struggle with this. We are not alone in it, just a lot of parents have a child that needs some more attention.

\section{Pausing}

Children and parents explained that they learned to pause more, to take a moment in which they meditate, turn inwards, 
or take rest. Within this category, children mainly described that they used meditation practices in challenging moments. They paused with what they were doing to take a moment to meditate, for example, "stopping with what I am doing" or "taking a few seconds to sigh." Several parents reported that they helped their child, and some children reported that they helped their parent, to meditate when they were in a challenging situation or feeling restless. An example of a child:

Which parts of the training helped you? The breathing space. I often did that one. I do that one when something goes wrong. Could you give me an example of when you try to do it? When I am angry. Or if I am in a fight with my little brother.

As compared to children, parents elaborated on this category more in depth. By pausing, they took a moment for themselves, or turned towards themselves, which they explained as closing themselves from everything around them, letting go of thoughts and stimuli, standing still with themselves. Also, they actively sought moments of rest, or sought the rest within themselves, whether for a few minutes or a whole afternoon. They, for example, did this when they were busy at work, or when they felt their stress was increasing. By doing this, some parents described they more consciously took themselves and their feelings into account when making a choice, and therefore took more moments of relaxation. Parents often used turning towards themselves and seeking rest as a way to pause before responding; taking a few seconds before responding, not taking immediate action, and delaying their reaction. They took time to get into their feelings, took a moment to take stock, to analyze thoughts, or to come back. An example of a parent:

It helps me in not getting completely stressed out. Sometimes this is acute, when the children do something or when they get into a fight. Then I take just one moment before I respond. But also for myself, so I do not stay stressed, so I am not the whole day stressing out with everything that needs to be done. Once in a while I think by myself: Okay, take it easy for a moment. And that helps by breathing or by listening to meditations.

\section{Being Aware}

Half of the children and all parents mentioned that they were more aware as a result of the training. They became aware of reactions within themselves, bodily sensations, thoughts, their own behavior, internal states of others, and social interactions from moment to moment. They were better able to observe from a distance what was happening and how they responded to situations in thoughts and feelings. They gained insight and understanding in what was happening, within themselves and in their surroundings, and thereby gained self-knowledge and understanding of social interactions. An example of a child, explaining that being aware helps in getting less distracted, followed by an example of a parent:

I better feel the distraction in my body. When I feel it, I mostly try to prevent it, when I am doing something important. And where do you feel that in your body? Or how does that feel? I feel like it is .. bubbling. As if something wants to get out. As if it all bubbles upwards and then wants to get out through my nose or through my ears. And how do you notice that earlier, the bubbling? That is because I earlier feel and know what is happening in my body.

It was just once in a while knowing what is happening with me, knowing what is happening with someone I am interacting with, and then responding differently than I would normally do. Although mapping the situation is not complete yet, it is surely a trigger for realizing: Gosh, this is happening now, hold a sec, this is something I recognize. Then I should not do this, I should do something else.

In this category of being aware, several parents also mentioned that they observed their child objectively, with fresh eyes, became more aware of the internal state of their child and improved their understanding of how their child is functioning. For example:

I think I have come to understand my son even better, and that helps. I just have to explain him a lot, explaining what is happening, why things are happening. He just needs a lot of attention, and you do not notice that because he is a very quiet person, but he does need the attention. We actually have always mentioned this at school, but at home we may have applied it less. How come that you now understand him better? Well, I think also by doing the training. I had to think about situations with my child each week. So then I reflected on it more, and started looking at my child in a different way than I used to. I observed more.

\section{Being in the Here and Now}

Several children and most parents described how they paid more attention to the here and now and were more in the present 
moment, when and since they applied mindfulness. They reported improved attention to the sensory and physical reality in the present moment, including sounds, eating, and their bodily sensations. Thereby, they were less in their heads or worrying about the past or the future. They carried out activities with more attention and focused their attention on the here and now. Parents also described that they paid more attention to the interactions with their children. By being in the here and now, several children and parents experienced less worry and more enjoyment. An example of a child, followed by an example of a parent:

I am trying to look what is really here, in the here and now. Thereby, in my mind I am less busy with all thoughts and stuff. What kind of thoughts for example? Well, that could be negative thoughts, but that does not need to be. For example, I was always very busy in my head and if I just focus on what is really there in that moment than it is less busy.

Mindfulness also means doing things with more attention. For example, since doing the mindfulness training I notice that more things stand out for me outside. If I walk outside I do not just go somewhere in a hurry, but I really observe where I am. More being in the moment.

\section{Determining a Strategy}

Some children and most parents improved their ability to determine a strategy to deal with challenging situations. They more consciously decided how they were going to respond and were able to come up with solutions, instead of reacting automatically or how they would normally do. Several participants explained mindfulness as thinking before doing. Several parents and a child described that in stressful situations or when feeling stressed, they said to themselves that it makes no sense to stress out, that they could better do something about it, let it go, or decrease their stress by pausing. Also, several parents and a child explained how they were better able to set priorities and to think about what is important and what is not when they were mindful or applying mindfulness exercises. Some parents explained that after they did something automatically, they now consciously determined their strategy for the next time. An example of a child, followed by an example of a parent:

I am curious how that works, how mindfulness helps in having fewer quarrels. I think less that I really have to go into it directly. And are you thinking something else now? Yes, I now think: Let me first calm down, and then maybe later go into it. If you go into it later, does that mean that you also go into it in a different way? Yes, because then I thought about it first, that I should not become really angry, that I can just say it a little less angry. It helps me when things come to me and I can take some distance. Then I get space in which I can choose myself what I want, without getting emotional or giving my natural reaction. That I do not immediately react on something without knowing if it is wise to do so. Now I can first think how I want to respond to it.

\section{Letting $\mathrm{Be}$}

Some children and most parents reported a process that we categorized as letting be. They described letting thoughts pass by, letting go of situations, and letting be of emotions, not trying to push them away. The children mostly described that they let their thoughts pass by and allowed their feelings instead of thinking they should not feel that way. Parents described this as well, and also described letting go of situations instead of reacting to them or immediately coming up with solutions. Several parents described this as accepting what is happening, accepting their feelings, and accepting their own limits. In addition, several parents described that they now more accepted their child being different from the norm and therefore in need of adjusted parenting. Several other parents described that they could let go of their child more easily; they now had more confidence that their child could handle difficult situations or would ask for help. It seems that some children and most parents learned how to be with difficult thoughts, emotions, and situations without reacting immediately to them, allowing them to be, and by doing so they could let go of these thoughts, emotions, and situations. An example of a parent:

What important things did you learn in the training that helped you to apply it? Of importance is that I try to clear my head, but off course that does not work. Thus I accept all thoughts that do come up, they are there anyway. I then also decide whether I am going to do something with these thoughts or not. I do not do anything with it for a moment. Do not think that you should always be totally free of thoughts, that is not going to happen. So I accept there are thoughts, I cannot stop that, but I can decide whether I do something with the thoughts or not.

Some children and parents expressed links between letting be and being milder and friendlier towards themselves. An example of a child:

Previously I was very strict on myself, for example that I did not allow myself to feel pain. Now it is just being 
kind to myself. Like: Hey, it may all be there, I do not need to change it. It is troublesome for a while, but I don't really have to change it.

\section{Being and Responding Calm}

Most children and all parents described aspects of being and responding calm. They became calmer after the training, or they became calmer after a meditation exercise. They mentioned feeling calmer, feeling more relaxed in the body, being calmer in the head, sleeping calmer, and being less stressed as aspects of being calm. An example of a child:

What do you notice after doing a meditation? I am calmer. And how does that help you? How does a meditation make you feel calmer, how do you think that works? Then I am a little calmer in my head.

In addition, parents and children described that they responded calmer in everyday challenging situations. Children mentioned they were less angry and more quickly relaxed after being angry. Parents also expressed this about their children. For example, a parent told about his child:

What I see of him is that if a boy says something like you are bad or I think you are bad on the soccer field, he used to be very sensitive for that. He could immediately run away being angry. Now it does not matter that much to him anymore. He can just say you are bad yourself, or he just continues playing. He also shows that in the classroom. I am not there off course, but previously he had a period that he was angry a lot and also reacted agitated in the classroom. And now the teachers have indicated that this is much less. Off course, he is developing himself as well, but I surely see a connection with the mindfulness training.

Half of the parents also described being more in control and internally stable. They experienced more balance and were less affected and emotionally involved by external situations. Children and parents appeared to respond less strongly driven by emotions, less unconscious, impulsive, and direct, but instead more patient, more quiet and with calmness in their voice, and were more weighing their words before saying them. An example of a parent:

Has anything changed for you through the mindfulness training? Yes, maybe some calmness in situations.
Especially when things happen, that I think: Okay, take it easy, and then I go into the situation. Could you give an example in which you can go calmer into the situation? Well, for example if something happens with the children. They are beating each other the brains out so to speak. In such moments, when I walk towards them I breath in deeply for a couple of breaths, just stay calm, and explain what is happening, whereas previously I would just go with the situation. In what way would you previously just go with the situation? I would start yelling as well, and such things. Now I try to solve it in a peaceful way.

\section{Attuning to Others}

Several children described an improvement in attuning to others. This is described in various ways. The family atmosphere appeared to be improved for several children; they mentioned there were less quarrels at home, improved interaction between parents and child, or less irritations with siblings. Some children described they were more open towards others or expressed their feelings more. For example:

Do you notice any changes in how things are at home? Yes, better. Okay, better. How do you notice? What makes it better? Because less often there are quarrels.

Has anything changed in what you do? No, not really, but I give more warnings. You give more warnings. Saying that someone needs to stop. If they then still continue, I become angry in the end, but I think that is logical. So you give more warnings on the moments that you would otherwise become angry, do I understand you correctly? Yes.

The parents described more often than the children themselves that their child improved in attuning to others after the training, after a training session, or after doing a meditation exercise. Several parents described that their child more often expressed his or her feelings, which increased the parents' understanding of their child, and increased the possibility of finding a solution together instead of getting into a quarrel. Also, several parents described their child was reachable more easily and more open to his or her surroundings following training. They talked more to classmates, friends, or parents. Some children told their parents more about what kept them busy, such as things at school or during therapy, and there was an increased back-and-forth conversation possible. Some parents mentioned their child was more responsive to the feelings of others, for example wishing well and expressing 
concern to a family member that was not feeling well. An example of a parent about her child:

We really have those moments together. We also talk about it sometimes, about how my daughter is doing, or what she is feeling. That is quite difficult for her, also because she has autism. But with mindfulness, for example the weather report exercise, this exercise is very useful for her to feel how she is doing. By labeling it with a type of weather we can use that label as a basis to talk about it. That helps her to express herself about how she is feeling. I think this makes us closer, because I better know what goes on in her mind.

All parents mentioned an improvement in attuning to others. Half of the parents described they were more consciously attuning their parenting to the needs of their child. Some parents explained that this was needed, because their automatic parenting behaviors fit less to the needs of their child with autism. They were more patient, explained situations in advance, and provided space for their child's frustration. For example, one of the parents informed the child each morning at what time breakfast would end. In addition, several parents described they expressed their feelings more towards their partner and sometimes towards their child. Some parents explained that by expressing their feelings, children and parents were better able to help each other. The connection between parent and child improved according to several parents. In addition to the improved family interactions, several parents described how they better attuned their behavior towards others, colleagues for example. They gave space to the opinion of others, improved in listening to others, discussed with instead of informed others, and took into account the abilities of others when organizing things at work or during holidays.

Also, some children mentioned that their parents helped them using a meditation exercise when they needed it. Several parents mentioned this themselves as well, and one child mentioned that he helped his family members to apply meditation exercises. Some parents mentioned that their child was advising meditation exercises to other family members. This implies that some parents and children recognized when their parent or child may need a mindfulness exercise, for example, because their interaction was tense, and were able to respond by advising a meditation exercise instead of reacting in a tense way in turn.

\section{Relations Among Change Processes}

The main change processes as described above were highly connected and interdependent. We constructed a model to reflect this interdependency and the general direction of the change processes (Fig. 1). One or both change processes of

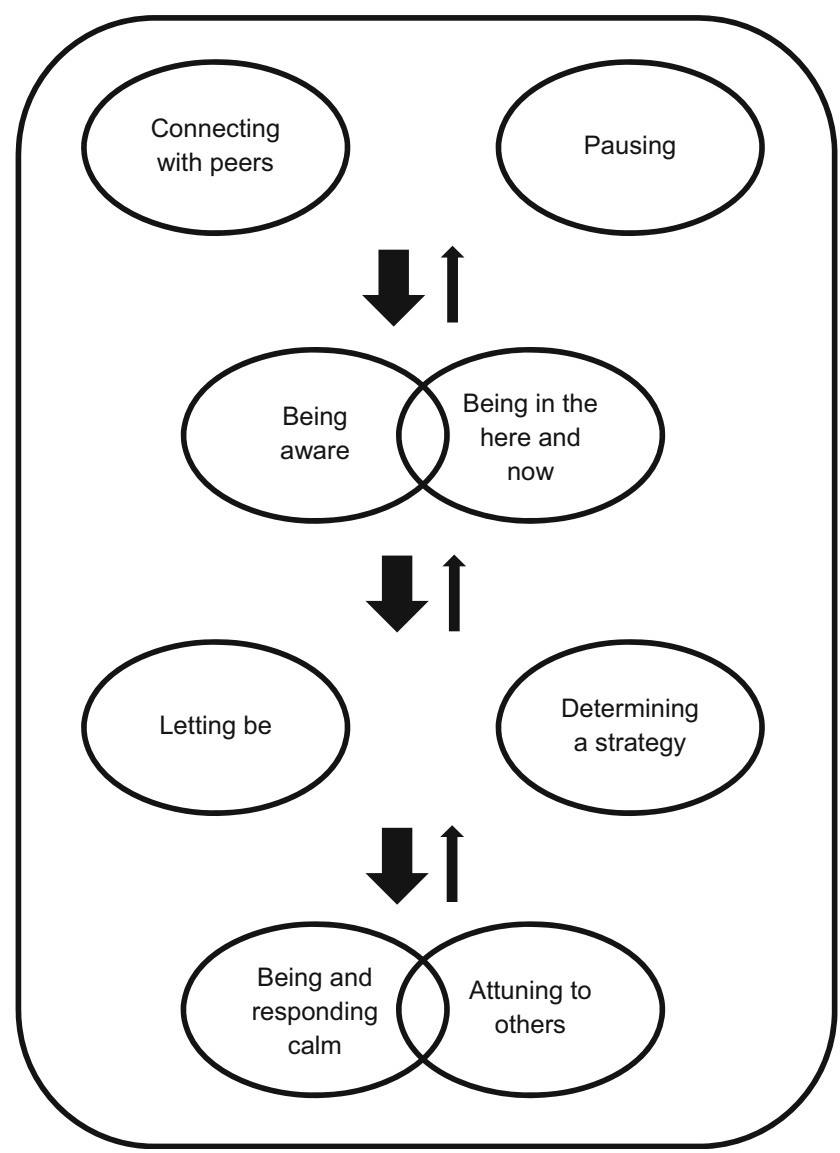

Fig. 1 Model of the main change processes that schematically represents their interdependency and possible directions. The big arrows reflect the general direction mostly present in the description of the children and parents, whereas the smaller arrows reflect that changes could flow in the other direction as well. Overlapping circles show that these change processes are partly overlapping

each layer could be taken, and change processes could be passed over, resulting in heterogeneous processes of change varying across participants and from moment to moment. To explicate, participants described how they responded calmly by pausing, being aware of the situation and their reaction to it, determining a strategy, and then responding. This could all happen in a matter of seconds or minutes. An example of a parent:

Mindful parenting was an eye-opener for me. Not that I am applying it every day now, but since the training I am more aware that that is an option, that I clearly have an option. When something is happening that is not nice, I have a choice to become angry, and I am more aware of that moment of choice. That was an eye-opener and I still take it with me. How does that moment of choice look like? Well, I am very aware of what is happening inside me, and what is happening to me in that moment. I feel that I am getting angry or there is something I do 
not like. I feel I am getting angry, and automatically I would have continued, but by taking a moment, by counting two, three, I can choose another way. By remaining very calm, becoming aware that this is not what my child means or will not yield what I would like, that becoming angry will only work counter-productively. Well, that all happens in split seconds, but the moment I become aware what is happening to me, that I feel it is rising. Well, it is very nice if that succeeds. Do you notice that it succeeds more? Yes, for sure.

As appears from this quote, the processes not always started at the top and ended at the bottom of the model. In this case, it started with being aware and moved up to pausing, back to being aware, then via determining a strategy resulting in responding calmly.

Instead of happening in split seconds, these change processes could also take a longer period. For example, by connecting with peers during the group training, parents exchanged experiences and consequently increased their insight - they became aware that their situation was easier in relation to the situation of other families, or that some struggles of other families with younger children were temporary and had already ended for them, and that other parents experienced difficulties as well. In turn, their process evolved to letting be; parents' acceptance of their situation and their allowing to feeling lousy sometimes about their situation increased. Also, increased awareness of what their child needed and increased acceptance of their child being different from other children led to the next step in the model, namely attuning their parenting behavior to the needs of their child.

As displayed in the model, several categories were overlapping. Being aware and being in the here and now were overlapping, because being aware was for a part being aware of the here and now. Also, attention for the present moment entailed being aware of that present moment. However, being aware also included awareness with some distance, a decentered awareness, of what the causes and consequences of the present moment were for one's reactions in thoughts, feelings, bodily sensations, for the internal states of others, and for their interaction. In addition, children and parents described being in the here and now several times as attending to the present moment in order to let go of experiences such as thoughts, pain, and worries. In this example a child explained how she learned to pause to attend to the present moment, in order to become calm and reactivate a beginners mind:

I think mindfulness is also focusing, either on myself or on something else, to focus my attention and to lose the tension. To clear my mind and be busy with something else, so me and my body can relax and as a result I will have a fresh look at the world afterwards.
Being and responding calm was partly overlapping with attuning to others. When participants responded calmly within a situation with someone else, this often resulted in a calmer reaction of that other person, indicating that responding calmly was a better attuned response. In addition, responding calmly included behaving less angry, more patient towards others, calmly explaining the situation or their feelings to the other, which also indicates a better attuned response. An example of a parent:

I notice that I am more patient. For example, if my daughter does not listen, I try in a patient way to make sure she will. Not immediately being the strict mother saying that now you have to brush your teeth, but just asking it again. I notice that she also reacts better to it. How do you notice that? She then does it earlier, whereas if I react more angry the second time, she also behaves with resistance, and she is more likely not doing it or doing it with difficulty, compared to when I say it again in a positive way.

\section{Divergent Themes}

In addition to the eight main change processes, some children and parents experienced other changes as well. Several children mentioned they were less distracted or were better able to concentrate at school when they were calmer in their head, after the mindfulness training, or directly after doing a meditation exercise. Further, some children mentioned they were doing better now at school. Only a few parents mentioned this improved concentration or schoolwork. Several other changes were mentioned by some parents about their child as well, such as better planning, being more motivated for change, undertaking more, and being more independent. In addition, several parents mentioned that they now regularly meditated, by themselves and sometimes with their child or the whole family. Some parents stated that only nuances changed, whereas some other parents mentioned mindfulness profoundly changed their way of living. Some parents and one child expressed that their opinion about mindfulness as being a bit "floaty" changed to mindfulness actually being quite "useful." Furthermore, some parents and children expressed being happier after the training.

Furthermore, several children and some parents did not experience change. This analysis did not focus on exploring for whom and how no change was experienced, and therefore this category is described only briefly here. Several children mentioned that nothing had changed for them, although some of these children did mention changes when asked about specific aspects, such as interaction with peers. In addition, some children mentioned aspects that had not changed, for example sleeping better. Some children who did not experience change 
also did not have or know what their aims were for the training. Several parents mentioned that nothing had changed with their child, although some of these parents mentioned small changes during the interview. Also, some parents mentioned that nothing had changed for themselves or for their partner. In addition to positive changes, most parents mentioned one or more difficulties that did not change after the mindfulness training, for example, their child's concentration difficulties. Some parents described how they experienced discomfort, became restless, or tired during meditations. In addition, several children and some parents mentioned that they did not continue with meditation exercises since the training was completed. This was either because they did not experience any positive change, or because it was difficult for them to persevere meditating regularly.

\section{Discussion}

In this study, we explored the change processes involved in a mindfulness-based program for children with ASD and their parents, the MYmind program, based on their experiences. Eight change processes were constructed in this grounded theory analysis which were interconnected and flowed into each other, namely connecting with peers, pausing, being aware, being in the here and now, letting be, determining a strategy, being and responding calm, and attuning to others. Children and parents both described these processes, although parents provided more depth in their explanations and more parents described each change process, whereas several children mentioned they did not experience much change. It seemed the children described the change process with less depth because of their level of development or their developmental disorder. These results provide the basis for a discussion on how these change processes relate to the science of mindfulness and its Buddhist foundations.

Several change processes seem to relate to the definition of mindfulness itself. Being in the here and now relates to the present-moment attention aspect of mindfulness, and being aware and letting be relate to the curious and accepting attitude aspect (Bishop et al. 2004; Kabat-Zinn 1994). However, although the change process of letting be clearly entailed acceptance, for some children and parents, it was not clear whether they described letting be and letting go in the sense of tolerating, or whether it also included non-judgmental acceptance. Future studies could investigate this further by explicitly asking about this difference when discussing letting be.

The Five Facet Mindfulness Questionnaire is one of the most used self-reported questionnaires of trait mindfulness (FFMQ; Baer et al. 2006). This multifaceted conceptualization of mindfulness partly resonates with the multiple change processes we identified. The facet non-reactivity to inner experience of the FFMQ resonates with the change processes being aware and letting be, because this subscale entails perceiving feelings and thoughts, as well as letting them be without reacting and letting them go. The facet observing of the FFMQ resonates with the overlap between being aware and being in the here and now. The facet acting with awareness resembles the change process being in the here and now. The facet non-judging of experience seems similar to the change process of letting be. Finally, the facet describing resonates with a subpart of attuning to others, namely expressing feelings. Only one item within the subscale non-reactivity in the FFMQ reflects the change process of pausing, and the other change processes (connecting with peers, determining a strategy, being and responding calm) are not included in the FFMQ conceptualization of mindfulness. An increase in self-reported trait mindfulness seems an important mechanism of change in MBPs, related to decreased psychological symptoms in adults with physical or psychological conditions (Alsubaie et al. 2017). The present study indicates that the facets of mindfulness may be mechanisms of change for children with ASD and their parents as well.

Parents described the change processes largely in relation to their parenting and their child. This is not surprising, because the parents received training in mindful parenting, rather than a general MBP. The change processes in relation to parenting are largely congruent with the conceptualization of mindful parenting, which entails six dimensions according to the factor structure of the Dutch version of the Interpersonal Mindfulness in Parenting Scale (IM-P; De Bruin et al. 2014). The factor listening with full attention resonates with attending to the parent-child interactions which was part of the change process being in the here and now. By providing this attention, parents increasingly became aware and understood their child's behavior, feelings, and thoughts, as part of the change process being aware. This resonates with the factor emotional awareness of the child. Also, parents described how they became aware of their own response to parenting situations, both their emotional response as well as their behavior. Awareness of their emotional response resonates with the factor emotional awareness of the self. The change process letting be entailed parents description of accepting their child and their own struggles in parenting. This resonates with the factor nonjudgmental acceptance of parental functioning (De Bruin et al. 2014), but also entails nonjudgmental acceptance of the child as described as part of mindful parenting by Duncan et al. (2009). The factor emotional non-reactivity in parenting resonates with the change process being and responding calm in parent-child interactions. The factor compassion for the child resonates mostly with attuning to the needs of the child, as part of the change process attuning to others. Compassion for self was not included in the factor structure of the Dutch IM-P (De Bruin et al. 2014), but was included in the description by Duncan et al. (2009) as part of the dimension 
compassion for self and child. Compassion for self came forward in the change process letting be, which included accepting parents' feelings and limits. Also, common humanity is a component of self-compassion (Neff 2003), which was an element of the change process connecting with peers. More improvement in mindful parenting after a mindful parenting training for parents of children with psychological conditions relates to more reduction of children's psychopathology (Meppelink et al. 2016). Thus, mindful parenting might be an important mechanism of change in the MYmind mindful parenting program for parents and their children with ASD.

The foundations of the practices used in contemporary MBPs lie in Buddhist traditions. Although over time developed in various lineages of Buddhism, the original teachings of the Buddha can be interpreted as a system of principles and practices that lead to insight and the overcoming of suffering (i.e., dukkha or dis-ease) for human beings (Bodhi 2011). The Buddhist concepts are not taught as such in most contemporary MBPs, which holds for the MYmind program as well. However, several change processes described in this study are consonant with Buddhist foundations of mindfulness. Viewing the change processes that resulted from this qualitative analysis from the perspective of Buddhist concepts is a way of back translation that contributes to the dialogue between the science of psychotherapy and the Buddhist traditions.

One of the six supreme virtues in Buddhism is kșanti, translated as patience, which is an antidote to anger. If a person has practiced patience sufficiently, the person will be able to respond calmly and non-automatically in challenging circumstances (Shantideva 2002; Tsomo 2015). The practice of patience seems to be an important element of what parents and children described in the change process pausing, explaining that they paused before responding in challenging situations, which in turn led to a calmer response. However, this change process also included pausing as a way to have moments of rest within a busy day or week. Future research could investigate whether these are different processes, or that pausing to take a rest is a way of practicing patience towards oneself.

The change process being in the here and now is akin to bare attention as it relates to the bare registering of what is observed in the here and now without reaction (Nyanaponika Thera 1988). This is part of the concept of mindfulness, but mindfulness contains much more. For example, it also contains an element of episodic memory (Anālayo 2017), and together with bare attention, this leads to understanding (Huxter 2015). Mindfulness is closely connected to other concepts that together lead to the overcoming of suffering. Two qualities that need to be cultivated to overcome suffering according to the Buddhist foundations are samatha, which refers to calm, peace, tranquility, and vipassana, which refers to insight (Harvey 2015). Samatha seems related to the change process being and responding calm, in which children and parents described that they became calm and were able to respond calmly, more balanced and less drawn to emotional reactions. Vipassana seems related to the change process being aware, in which children and parents described that they gained insights and understanding by being more aware of what was happening within themselves and in their surroundings. In samatha meditation, the single-pointed concentration on one object, such as the breath, is taught. This is included in the MYmind program during several meditation exercises on the breath and the body. In vipassana meditation, attention is opened out to observe each passing sensory or mental object, to cultivate the quality of insight and recognize the three features that apply to all phenomena: impermanence (anicca); unsatisfactoriness or suffering (dukkha); and not-self (anatta). The MYmind program includes several practices to become aware of this impermanence. For example, by the meditation on thoughts, participants train to recognize that thoughts arise and cease from moment to moment; they are temporary. However, the other two insights of vipassana are not specifically explained and practiced in MYmind, and the insights and understanding that were gained by the children and parents cannot be ascribed to these two insights of the teachings of the Buddha. Rather, the results imply an increased understanding of the causes and consequences of human interaction from moment to moment.

The Buddhist teachings do not describe a set of practices aimed at the overcoming of specific suffering, but are aimed at overcoming all suffering (i.e., dukkha, the unsatisfactoriness of all conditioned phenomena), thus including the suffering of others. Ethics forms an important pillar in the Buddhist path to liberation, in the sense that what is ethical is what leads to wellbeing and not to suffering (Maex 2011; Stanley et al. 2018). It seems that the children and parents also cultivated behavior that could lead to wellbeing of others, reflected in the change process attuning to others. Besides, several parents expressed that mindful parenting not only meant awareness of and attuning to their child, but at the same time awareness of and attuning to their own feelings. This seems related to the Buddhist idea in which caring for self and others go hand in hand. By caring for oneself, one cares for others. By caring for others, one cares for oneself (Stanley 2015). Although the MYmind program does not include explicit training in ethics, aspects of this program are relational. For example, the MYmind child program includes a session on awareness of feelings of self and others, and the MYmind parent program focuses on the parent-child interactions. Although there are concerns on whether contemporary MBPs should include explicit teaching of Buddhist ethics in order to prevent it from being a training of solely bare attention (Kabat-Zinn 2017; Monteiro et al. 2015), this contemporary MBP seems to cultivate other qualities described in its Buddhist foundations as well.

The change process attuning to others might be an important change for the children with ASD, given its supremacy to 
ASD symptoms. However, it is neither implied here that all children improved in attuning to others nor that they improved in the long run. A more nuanced interpretation would be that children with ASD seemed better able to express their feelings when responding mindfully, thereby their parents and other family members were better able to attune to them, leading to an improved family atmosphere. In addition, some children appeared to be more open and responsive to feelings of others. Previous studies of MBPs for children with ASD or their parents also reported improved family relationships (Kennedy 2017; Ridderinkhof et al. 2018a; Singh et al. 2014) and social responsiveness (De Bruin et al. 2015; Ridderinkhof et al. 2018a). The change process attuning to others seemed closely related to the change process being aware. Several parents described being aware of internal states of others, and being aware and increased understanding of social interactions as a precursor of attuning to others. They described this about themselves and about their child; however, children did not mention more awareness of internal states and social interactions. These results suggest that the MYmind program promotes empathy in the parents and some children with ASD, in line with the theoretical account that mindfulness might cultivate empathy, considered as a moment-tomoment process, by increased emotional awareness and understanding (Block-Lerner et al. 2007).

The combined change processes reflect a process of self-regulation, the self-control of thought, action, and emotion. According to the iterative reprocessing model, self-regulation is influenced by top-down processes, such as inhibition and reflection, and by bottom-up processes, such as arousal, anxiety, and motivation (Zelazo 2015). Cultivating the top-down processes and regulating the bottom-up processes would thus increase self-regulation, and mindfulness may thereby increase selfregulatory skills (Zelazo and Lyons 2012). In this study, several change processes seem to reflect an increased top-down processing. Children and parents learned to pause, become aware of the situation and their inner reactions to it, and determine a strategy before responding. Also, they learned to let be and let go of their thoughts and feelings instead of reacting to them, which seems to reflect an attenuated influence of bottom-up processes on their behavior. Together, this self-regulation process resulted in being and responding calm.

\section{Limitations and Strengths}

This study has several limitations, which should be taken into account when interpreting the results. First, although the gender of the participating children was balanced between girls and boys, this does not reflect the ASD population (Loomes et al. 2017). Second, participants were interviewed once and theoretical sampling was conducted on subsequent interviews with new participants, which limited the possibility of following up on earlier statements of participants (Charmaz 2014). Third, the interviews were conducted, transcribed, and for a large part analyzed in Dutch. By translating the results into English some nuances in meaning might have been lost in translation. Fourth, although inherent to constructivist grounded theory, we as researchers were involved in the construction of this theory based on the interviews. This is our interpretation of the interviews with this group of participants, which could limit generalizations to other groups of participants and researchers (Does et al. 2018; Krägeloh 2018).

This study also has several strengths. First, we not only listened to the experiences of the parents, but also to the experiences of the children with ASD themselves. Second, we asked participants whether they noticed changes in the other family members, which provided multi-informant and inter-relational data. Third, women and men were well presented in both parents and children, and families from multiple treatment centers participated, which strengthens the generalization.

In conducting this study, we intended to deepen the understanding of how an MBP could benefit children with ASD and their parents. The model of change processes that resulted from the constructivist qualitative analysis entails sharing experiences and an attentive, conscious and patient way of regulating emotions, thoughts, and behavior to cope with challenging experiences and social interactions. The model as presented in this study should be taken as a provisional model of the mechanisms of change involved in the MYmind program for children with ASD and their parents. Future studies should investigate whether these change processes hold if other methodologies are used. Also, future studies could investigate whether these change processes apply to other MPBs for parents or children with ASD as well.

Acknowledgments We are grateful to the children and parents for their contribution by participating in this study. We thank the student assistants of the University of Amsterdam for their work in transcribing the interviews.

\section{Compliance with Ethical Standards}

All procedures performed in this study were in accordance with the ethical standards of the national Medical Research Involving Human Subjects Act and with the Declaration of Helsinki 1964 and its later amendments. Written informed consent was obtained from all participants of 12 years and older and from all parents of the participating children. The study was approved by the Medical Ethics Committee of the Academic Medical Center (AMC) in Amsterdam (NL43720.018.13).

Conflict of Interest Author Susan M. Bögels owns shares in UvA minds, one of the participating treatment centers. The other authors report no conflict of interest.

Open Access This article is distributed under the terms of the Creative Commons Attribution 4.0 International License (http:// creativecommons.org/licenses/by/4.0/), which permits unrestricted use, distribution, and reproduction in any medium, provided you give appropriate credit to the original author(s) and the source, provide a link to the Creative Commons license, and indicate if changes were made. 


\section{References}

Alsubaie, M., Abbott, R., Dunn, B., Dickens, C., Keil, T. F., Henley, W., \& Kuyken, W. (2017). Mechanisms of action in mindfulness-based cognitive therapy (MBCT) and mindfulness-based stress reduction (MBSR) in people with physical and/or psychological conditions: a systematic review. Clinical Psychology Review, 55, 74-91. https:// doi.org/10.1016/j.cpr.2017.04.008.

American Psychiatric Association. (1994). Diagnostic and statistical manual of mental disorders (4th ed.). Washington, DC: Author.

American Psychiatric Association. (2013). Diagnostic and statistical manual of mental disorders (5th ed.). Washington, DC: Author.

Anālayo, B. (2017). Early Buddhist meditation studies. Barre: Barre Center for Buddhist Studies.

Baer, R. A. (2003). Mindfulness training as a clinical intervention: a conceptual and empirical review. Clinical Psychology: Science and Practice, 10, 125-143. https://doi.org/10.1093/clipsy/bpg015.

Baer, R. A., Smith, G. T., Hopkins, J., Krietemeyer, J., \& Toney, L. (2006). Using self-report assessment methods to explore facets of mindfulness. Assessment, 13, 27-45. https://doi.org/10.1177/ 1073191105283504.

Billington, T. (2006). Working with autistic children and young people: sense, experience and the challenges for services, policies and practices. Disability \& Society, 21, 1-13. https://doi.org/10.1080/ 09687590500373627.

Bishop, D. V., Maybery, M., Maley, A., Wong, D., Hill, W., \& Hallmayer, J. (2004). Using self-report to identify the broad phenotype in parents of children with autistic spectrum disorders: a study using the autismspectrum quotient. Journal of Child Psychology and Psychiatry, 45, 1431-1436. https://doi.org/10.1111/j.1469-7610.2004.00325.x.

Block-Lerner, J., Adair, C., Plumb, J. C., Rhatigan, D. L., \& Orsillo, S. M. (2007). The case for mindfulness-based approaches in the cultivation of empathy: does nonjudgmental, present-moment awareness increase capacity for perspective-taking and empathic concern? Journal of Marital and Family Therapy, 33, 501-516. https://doi. org/10.1111/j.1752-0606.2007.00034.

Bodhi, B. (2011). What does mindfulness really mean? A canonical perspective. Contemporary Buddhism, 12, 19-39. https://doi.org/10. 1080/14639947.2011.564813.

Bögels, S., \& Restifo, K. (2014). Mindful parenting: a guide for mental health practitioners. New York: Springer.

Bögels, S., Hoogstad, B., van Dun, L., de Schutter, S., \& Restifo, K. (2008). Mindfulness training for adolescents with externalizing disorders and their parents. Behavioural and Cognitive Psychotherapy, 36, 193-209. https://doi.org/10.1017/S1352465808004190.

Bohlmeijer, E., Prenger, R., Taal, E., \& Cuijpers, P. (2010). The effects of mindfulness-based stress reduction therapy on mental health of adults with a chronic medical disease: a meta-analysis. Journal of Psychosomatic Research, 68, 539-544. https://doi.org/10.1016/j. jpsychores.2009.10.005.

Cachia, R. L., Anderson, A., \& Moore, D. W. (2016a). Mindfulness in individuals with autism spectrum disorder: a systematic review and narrative analysis. Review Journal of Autism and Developmental Disorders, 3, 165-178. https://doi.org/10.1007/s40489-016-0074-0.

Cachia, R. L., Anderson, A., \& Moore, D. W. (2016b). Mindfulness, stress and well-being in parents of children with autism spectrum disorder: a systematic review. Journal of Child and Family Studies, 25, 1-14. https://doi.org/10.1007/s10826-015-0193-8.

Charmaz, K. (2014). Constructing grounded theory (2nd ed.). London: Sage Publications Ltd..

Corbett, B. A., \& Simon, D. (2014). Adolescence, stress and cortisol in autism spectrum disorders. OA autism, 1, 1-9.

De Bruin, E. I., Zijlstra, B. J., Geurtzen, N., van Zundert, R. M., van de Weijer-Bergsma, E., Hartman, E. E., ... \& Bögels, S. M. (2014). Mindful parenting assessed further: psychometric properties of the
Dutch version of the Interpersonal Mindfulness in Parenting Scale (IM-P). Mindfulness, 5, 200-212. https://doi.org/10.1007/s12671-0120168-4.

De Bruin, E. I., Blom, R., Smit, F. M., Van Steensel, F. J., \& Bögels, S. M. (2015). MYmind: mindfulness training for youngsters with autism spectrum disorders and their parents. Autism, 19, 906-914. https:// doi.org/10.1177/1362361314553279.

Does, S., Ellemers, N., Dovidio, J. F., Norman, J. B., Mentovich, A., van der Lee, R., \& Goff, P. A. (2018). Implications of research staff demographics for psychological science. American Psychologist, 73, 639-650. https://doi.org/10.1037/amp0000199.

Duncan, L. G., Coatsworth, J. D., \& Greenberg, M. T. (2009). A model of mindful parenting: implications for parent-child relationships and prevention research. Clinical Child and Family Psychology Review, 12, 255-270. https://doi.org/10.1007/s10567-009-0046-3.

Dykens, E. M., Fisher, M. H., Taylor, J. L., Lambert, W., \& Miodrag, N. (2014). Reducing distress in mothers of children with autism and other disabilities: a randomized trial. Pediatrics, 134, 454-463. https://doi.org/10.1542/peds.2013-3164.

Glaser, B. G., \& Strauss, A. L. (1967). The discovery of grounded theory: strategies for qualitative research. Chicago: Adeline Publisher Co..

Happé, F., \& Frith, U. (2006). The weak coherence account: detailfocused cognitive style in autism spectrum disorders. Journal of Autism and Developmental Disorders, 36, 5-25. https://doi.org/10. 1007/s10803-005-0039-0.

Harvey, P. (2015). Mindfulness in Theravada samatha and vipassana meditations, and in secular mindfulness. In E. Shonin, W. Van Gordon, \& N. N. Singh (Eds.), Buddhist foundations of mindfulness (pp. 115-138). New York: Springer.

Hastings, R. P. (2002). Parental stress and behaviour problems of children with developmental disability. Journal of Intellectual and Developmental Disability, 27, 149-160. https://doi.org/10.1080/ 1366825021000008657.

Hastings, R. P. (2003). Child behaviour problems and partner mental health as correlates of stress in mothers and fathers of children with autism. Journal of Intellectual Disability Research, 47, 231-237. https://doi.org/10.1046/j.1365-2788.2003.00485.x.

Hill, E. L. (2004). Executive dysfunction in autism. Trends in Cognitive Sciences, 8, 26-32.

Hölzel, B. K., Lazar, S. W., Gard, T., Schuman-Olivier, Z., Vago, D. R., \& Ott, U. (2011). How does mindfulness meditation work? Proposing mechanisms of action from a conceptual and neural perspective. Perspectives on Psychological Science, 6, 537-559. https://doi. org/10.1177/1745691611419671.

Huxter, M. (2015). Mindfulness and the Buddha's noble eightfold path. In E. Shonin, W. Van Gordon, \& N. N. Singh (Eds.), Buddhist foundations of mindfulness (pp. 29-54). New York: Springer.

Hwang, Y. S., Kearney, P., Klieve, H., Lang, W., \& Roberts, J. (2015). Cultivating mind: mindfulness interventions for children with autism spectrum disorder and problem behaviours, and their mothers. Journal of Child and Family Studies, 24, 3093-3106. https://doi. org/10.1007/s10826-015-0114-x.

Kabat-Zinn, J. (1982). An outpatient program in behavioral medicine for chronic pain patients based on the practice of mindfulness meditation: theoretical considerations and preliminary results. General Hospital Psychiatry, 4, 33-47. https://doi.org/10.1016/01638343(82)90026-3.

Kabat-Zinn, J. (1994). Where ever you go, there you are: mindfulness meditation in everyday life. New York: Hyperion.

Kabat-Zinn, J. (2017). Too early to tell: the potential impact and challenges - ethical and otherwise - inherent in the mainstreaming of dharma in an increasingly dystopian world. Mindfulness, 8,1125 1135. https://doi.org/10.1007/s12671-017-0758-2.

Kennedy, J. C. (2017). Experiences of mothers of children with autism spectrum disorder in a mindful parenting course (doctoral 
dissertation). Retrieved from ProQuest Dissertations Publishing. (Accession No. 10276401).

Krägeloh, C. U. (2018). Phenomenological research fails to capture the experience of nondual awareness. Mindfulness. Advance of Print. https://doi.org/10.1007/s12671-018-0995-z.

Kuyken, W., Warren, F. C., Taylor, R. S., Whalley, B., Crane, C., Bondolfi, G., et al. (2016). Efficacy of mindfulness-based cognitive therapy in prevention of depressive relapse: an individual patient data meta-analysis from randomized trials. JAMA Psychiatry, 73, 565-574. https://doi.org/10.1001/jamapsychiatry.2016.0076.

Loomes, R., Hull, L., \& Mandy, W. P. L. (2017). What is the male-to-female ratio in autism spectrum disorder? A systematic review and meta-analysis. Journal of the American Academy of Child and Adolescent Psychiatry, 56, 466-474. https://doi.org/10.1016/j.jaac.2017.03.013.

Lord, C., Risi, S., Lambrecht, L., Cook, E. H., Leventhal, B. L., DiLavore, P. C., ... \& Rutter, M. (2000). The Autism Diagnostic Observation Schedule - Generic: a standard measure of social and communication deficits associated with the spectrum of autism. Journal of Autism and Developmental Disorders, 30, 205-223. https://doi.org/10.1023/A:1005592401947.

Lord, C., Rutter, M., DiLavore, P. C., Risi, S., Gotham, K., \& Bishop, S. (2012). Autism diagnostic observation schedule (2nd ed.). Torrance: Western Psychological Services.

Lutz, A., Slagter, H. A., Dunne, J. D., \& Davidson, R. J. (2008). Attention regulation and monitoring in meditation. Trends in Cognitive Sciences, 12, 163-169. https://doi.org/10.1016/j.tics.2008.01.005.

Ma, S. H., \& Teasdale, J. D. (2004). Mindfulness-based cognitive therapy for depression: replication and exploration of differential relapse prevention effects. Journal of Consulting and Clinical Psychology, 72, 31-40. https://doi.org/10.1037/0022-006X.72.1.31.

Maex, E. (2011). The Buddhist roots of mindfulness training: a practitioners view. Contemporary Buddhism, 12, 165-175. https://doi. org/10.1080/14639947.2011.564835.

Meppelink, R., de Bruin, E. I., Wanders-Mulder, F. H., Vennik, C. J., \& Bögels, S. M. (2016). Mindful parenting training in child psychiatric settings: heightened parental mindfulness reduces parents' and children's psychopathology. Mindfulness, 7, 680-689. https://doi.org/ 10.1007/s12671-016-0504-1.

Monteiro, L. M., Musten, R. F., \& Compson, J. (2015). Traditional and contemporary mindfulness: finding the middle path in the tangle of concerns. Mindfulness, 6, 1-13. https://doi.org/10.1007/s12671014-0301-7.

Neece, C. L. (2014). Mindfulness-based stress reduction for parents of young children with developmental delays: implications for parental mental health and child behavior problems. Journal of Applied Research in Intellectual Disabilities, 27, 174-186. https://doi.org/ $10.1111 /$ jar.12064.

Neff, K. D. (2003). The development and validation of a scale to measure self-compassion. Self and Identity, 2, 223-250. https://doi.org/10. 1080/15298860390209035.

Ridderinkhof, A., de Bruin, E. I., Blom, R., \& Bögels, S. M. (2018a). Mindfulness-based program for children with autism spectrum disorder and their parents: direct and long-term improvements. Mindfulness, 9, 773-791. https://doi.org/10.1007/s12671-017-0815-x.

Ridderinkhof, A., de Bruin, E. I., van den Driesschen, S., \& Bögels, S. M. (2018b). Attention in children with autism spectrum disorder and effects of a mindfulness-based program. Journal of Attention Disorders. Advance online publication. https://doi.org/10.1177/ 1087054718797428

Segal, Z. V., Williams, J. M. G., \& Teasdale, J. D. (2012). Mindfulnessbased cognitive therapy for depression. New York: Guilford Press.

Semple, R. J. (2019). Yoga and mindfulness for youth with autism spectrum disorder: review of the current evidence. Child and Adolescent Mental Health, 24(1), 12-18 https://doi.org/10.1111/camh.12295.
Sequeira, S., \& Ahmed, M. (2012). Meditation as a potential therapy for autism: a review. Autism Research and Treatment, 2012, 1-11. https://doi.org/10.1155/2012/835847.

Shantideva. (2002). Guide to the Bodhisattva's way of life. Ulverston: Tharpa Publications.

Shonin, E., Van Gordon, W., \& Singh, N. N. (2015). Buddhist foundations of mindfulness. New York: Springer.

Simonoff, E., Pickles, A., Charman, T., Chandler, S., Loucas, T., \& Baird, G. (2008). Psychiatric disorders in children with autism spectrum disorders: prevalence, comorbidity, and associated factors in a population-derived sample. Journal of the American Academy of Child \& Adolescent Psychiatry, 47, 921-929. https://doi.org/10. 1097/CHI.0b013e318179964f.

Singh, N. N., Lancioni, G. E., Winton, A. S., Karazsia, B. T., Myers, R. E., Latham, L. L., \& Singh, J. (2014). Mindfulness-based positive behavior support (MBPBS) for mothers of adolescents with autism spectrum disorder: effects on adolescents' behavior and parental stress. Mindfulness, 5, 646-657. https://doi.org/10.1007/s12671-014-0321-3.

Stanley, S. (2015). Sila and Sati: an exploration of ethics and mindfulness in Pali Buddhism and their implications for secular mindfulnessbased applications. In E. Shonin, W. Van Gordon, \& N. N. Singh (Eds.), Buddhist foundations of mindfulness (pp. 89-114). New York: Springer.

Stanley, S., Purser, R., \& Singh, N. N. (2018). Handbook of ethical foundations of mindfulness. New York: Springer.

Teasdale, J. D., Moore, R. G., Hayhurst, H., Pope, M., Williams, S., \& Segal, Z. V. (2002). Metacognitive awareness and prevention of relapse in depression: empirical evidence. Journal of Consulting and Clinical Psychology, 70, 275-287. https://doi.org/10.1037//0022-006X.70.2.275.

Thera, N. (1988). The heart of Buddhist meditation: a handbook of mental training based on the Buddha's way of mindfulness. York Beach: Samuel Weiser, Inc..

Tsomo, K. L. (2015). Mindfulness and the six perfections. In E. Shonin, W. Van Gordon, \& N. N. Singh (Eds.), Buddhist foundations of mindfulness (pp. 139-158). New York: Springer.

Van de Weijer-Bergsma, E., Formsma, A. R., De Bruin, E. I., \& Bögels, S. M. (2012). The effectiveness of mindfulness training on behavioral problems and attentional functioning in adolescents with ADHD. Journal of Child and Family Studies, 21, 775-787. https://doi.org/ 10.1007/s10826-011-9531-7.

Van der Oord, S., Bögels, S. M., \& Peijnenburg, D. (2012). The effectiveness of mindfulness training for children with ADHD and mindful parenting for their parents. Journal of Child and Family Studies, 21, 139-147. https://doi.org/10.1007/s10826-011-9457-0.

Van Steijn, D. J., Oerlemans, A. M., Van Aken, M. A., Buitelaar, J. K., \& Rommelse, N. N. (2014). The reciprocal relationship of ASD, ADHD, depressive symptoms and stress in parents of children with ASD and/or ADHD. Journal of Autism and Developmental Disorders, 44, 1064-1076. https://doi.org/10.1007/s10803-0131958-9.

Zelazo, P. D. (2015). Executive function: reflection, iterative reprocessing, complexity, and the developing brain. Developmental Review, 38, 5568. https://doi.org/10.1016/j.dr.2015.07.001.

Zelazo, P. D., \& Lyons, K. E. (2012). The potential benefits of mindfulness training in early childhood: a developmental social cognitive neuroscience perspective. Child Development Perspectives, 6, 154 160. https://doi.org/10.1111/j.1750-8606.2012.00241.x.

Publisher's Note Springer Nature remains neutral with regard to jurisdictional claims in published maps and institutional affiliations. 